ASTHMA

\title{
Outcome of occupational asthma after cessation of exposure: a systematic review
}

\author{
George Rachiotis, Rashna Savani, Andrew Brant, Stephanie J MacNeill, Anthony Newman Taylor, \\ Paul Cullinan
}

See end of article for authors' affiliations

......................

Correspondence to: P Cullinan, Department of Occupational and Environmental Medicine, Imperial College (NHLI), $1 \mathrm{~b}$ Manresa Road, London SW3 6LR, UK; p.cullinan@ imperial.ac.uk

Received 6 March 2006 Accepted 13 August 2006 Published Online First 13 October 2006
Background: Patients with occupational asthma, and their medical advisers, need valid information about the prognosis of their disease.

Methods: A systematic review of the published literature on the symptomatic and functional outcomes of occupational asthma was carried out after avoidance of exposure to the causative agent. Through a full search of electronic and bibliographic sources, original studies documenting complete recovery from asthma ( $n=39,1681$ patients) or improvement in non-specific bronchial hyper-responsiveness (NSBHR; $n=28,695$ patients) were identified. The median duration of follow-up was 31 (range 6-240) months for studies of symptomatic recovery and 37 (6-240) months for studies of NSBHR. Most studies were of patients recruited from special clinics.

Results: Reported rates of symptomatic recovery varied from $0 \%$ to $100 \%$, with a pooled estimate of $32 \%$ (95\% Cl $26 \%$ to $38 \%)$. These rates were lower with increasing age $(p=0.019)$ and among clinic based populations $(p=0.053)$. Patients with the shortest durations of exposure ( $\leqslant 76$ months) had the highest rate of recovery (36\%; $95 \% \mathrm{Cl} 25 \%$ to $50 \%$ ), but the effect was not linear. The pooled prevalence of persistent NSBHR at follow-up was $73 \%$ (95\% Cl 66\% to 79\%). This figure was higher among patients whose disease was due to high-molecular-weight agents $(p=0.006)$ and, less clearly, those from clinic-based populations $(p=0.561)$. In between-study comparisons, no clear patterns of improvement relating to total duration of exposure or follow-up were found. From within-study comparisons there was some evidence that a shorter duration of symptoms was associated with a higher rate of symptomatic recovery.

Conclusion: The available data on the prognosis of occupational asthma are insufficiently consistent to allow confident advice to be given to patients with the disease. Clinicians and epidemiologists with an interest in this disease should consider a collaborative and carefully standardised study of the prognosis of occupational asthma.

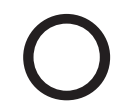
ccupational asthma may be defined as reversible airway obstruction that is induced by workplace exposure to airborne dusts, gases, vapours or fumes. ${ }^{1}$ In industrialised countries, it is the most commonly reported occupational lung disease; despite intensive preventive measures there is little evidence that its overall incidence is declining. ${ }^{2}$

Patients with a diagnosis of occupational asthma are generally advised that further exposure to the causative agent will lead to continuing and worsening symptoms and may adversely affect outcome. As such agents are usually encountered only at work, avoidance of exposure is achieved mainly by relocation in the workplace or, more commonly, by a change in occupation. Respiratory protective equipment may be helpful, but its effectiveness has been studied only in a few small-scale, short-term studies ${ }^{3}$; in any case, it is rarely practicable in the long term. Thus, the diagnosis of occupational asthma requires patients (and their employers) to confront important social and economic decisions. To assist them, they need clear information on the prognosis of the disease should further exposure should be avoided. In addition, occupational asthma is a potentially valuable model for the study of allergen avoidance in adult disease.

We carried out a systematic review of published studies of the outcome, and determinants of outcome, of occupational asthma after avoidance of the causative agent. In this way, we aimed to understand how comprehensive and how consistent the available information was; and whether further research was necessary.

\section{METHODS}

As far as we are aware, no prior systematic review of this topic is available. We searched, electronically, Medline and EMBASE databases from, respectively, 1996 and 1974 to March 2004. We further examined the reference lists of relevant articles identified in this manner. We selected for inclusion in the review all original, published studies in any language, reporting the outcome of patients with occupational asthma after the cessation of causative exposure. We excluded studies of "irritant-induced asthma" and those where patients had been relocated to "low exposure" positions at work. We also excluded studies where it was not possible to distinguish the outcomes of patients who had avoided exposure from those of patients with persistent exposure after diagnosis.

We did not apply any assessment of study quality, nor did we consider in detail the methods by which a diagnosis of occupational asthma had been reached. The studies that we identified used a large number of diverse outcome measures; from these we selected two that we thought were clinically relevant and that were most often reported: complete symptomatic recovery from asthma and improvement in non-specific bronchial hyper-responsiveness (NSBHR). As potential determinants of outcome, we examined the effects of age, agent, setting and durations of both exposure and follow-up after cessation of exposure. Data were extracted, independently by

Abbreviations: $\mathrm{HMW}$, high molecular weight; LMW, low molecular weight; NSBHR, non-specific bronchial hyper-responsiveness 
Table 1 Characteristics of the reviewed studies of symptomatic recovery

\begin{tabular}{|c|c|c|c|c|c|c|}
\hline Year & Setting & Agent & $\begin{array}{l}\text { Subjects } \\
\text { at follow-up }\end{array}$ & $\begin{array}{l}\text { Follow-up } \\
\text { (months) }\end{array}$ & Country & Reference \\
\hline 1977 & Clinic & Flour & 168 & Not available & Europe & Meyer $^{4}$ \\
\hline 1977 & Clinic & Red cedar & 38 & 18 & Canada & Chan-Yeung $^{5}$ \\
\hline 1982 & Clinic & Colophony & 20 & 29 & Europe & Burge $^{6}$ \\
\hline 1982 & Clinic & Red cedar & 75 & 42 & Canada & Chan-Yeung ${ }^{7}$ \\
\hline 1984 & Clinic & Isocyanates & 12 & 25 & Europe & Paggiaro $^{8}$ \\
\hline 1985 & Clinic & Various & 32 & 25 & Canada & Hudson 9 \\
\hline 1985 & Clinic & Crab & 31 & 12 & Canada & Hudson ${ }^{9}$ \\
\hline 1987 & Clinic & Isocyanates & 50 & 48 & Europe & Lozewicz $^{10}$ \\
\hline 1987 & Clinic & Red cedar & 136 & 48 & Canada & Chan-Yeung ${ }^{11}$ \\
\hline 1987 & Clinic & Isocyanates & 20 & 30 & Europe & Rosenberg $^{12}$ \\
\hline 1988 & Clinic & Isocyanates & 30 & 10 & Europe & $M_{a p p}^{13}$ \\
\hline 1988 & Clinic & Red cedar & 17 & 47 & Canada & Chan-Yeung $^{14}$ \\
\hline 1989 & Clinic & Various & 32 & 28 & Canada & Allard ${ }^{15}$ \\
\hline 1989 & Clinic & Various & 28 & 70 & Canada & Allard ${ }^{15}$ \\
\hline 1989 & Workplace & Aluminium & 43 & 60 & New Zealand & O'Donnell' ${ }^{16}$ \\
\hline 1992 & Workplace & Aluminium & 12 & 23 & Europe & Soyseth ${ }^{17}$ \\
\hline 1992 & Clinic & Isocyanates & 6 & 6 & Europe & Saetta $^{18}$ \\
\hline 1993 & Clinic & Isocyanates & 43 & 60 & Europe & Pisati $^{19}$ \\
\hline 1993 & Clinic & Various & 18 & 14 & Europe & Moscato $^{20}$ \\
\hline 1993 & Clinic & Red cedar & 80 & 57 & Canada & Marabini ${ }^{21}$ \\
\hline 1994 & Clinic & Isocyanates & 28 & 82 & Europe & Marabini $^{22}$ \\
\hline 1994 & Clinic & Cobalt & 8 & 36 & Europe & Pisati ${ }^{23}$ \\
\hline 1994 & Workplace & Platinum salts & 24 & 19 & Europe & Merget $^{24}$ \\
\hline 1995 & Clinic & Isocyanates & 10 & 13 & Europe & Saetta $^{25}$ \\
\hline 1995 & Workplace & Anhydrides & 6 & 12 & USA & Grammer $^{26}$ \\
\hline 1996 & Clinic & Various & 32 & 18 & Canada & $\mathrm{Malo}^{27}$ \\
\hline 1996 & Clinic & Various & 15 & 40 & Canada & Lemiere $^{28}$ \\
\hline 1996 & Workplace & Anhydrides & 11 & 48 & USA & Grammer $^{29}$ \\
\hline 1997 & Clinic & Isocyanates & 35 & 24 & Korea & Park ${ }^{30}$ \\
\hline 1998 & Clinic & Various & 55 & 31 & USA & Gassert ${ }^{31}$ \\
\hline 1998 & Clinic & Various & 305 & Not available & Europe & Ross $^{32}$ \\
\hline 1998 & Clinic & Enzymes & 3 & Not available & Europe & $\operatorname{Sen}^{33}$ \\
\hline 1998 & Workplace & Anhydrides & 6 & 240 & Europe & Barker $^{34}$ \\
\hline 1999 & Clinic & Various & 13 & 12 & Europe & Moscato $^{35}$ \\
\hline 2002 & Clinic & Latex & 16 & 56 & Europe & Vandenplas ${ }^{36}$ \\
\hline 2002 & Clinic & Isocyanates & 41 & 67 & Korea & Park ${ }^{37}$ \\
\hline 2003 & Clinic & Persulphate & 5 & 23 & Europe & Munoz ${ }^{38}$ \\
\hline 2003 & Clinic & Isocyanates & 74 & 132 & Europe & Padoan $^{39}$ \\
\hline 2004 & Clinic & Various & 103 & 104 & Canada & Maghni $^{40}$ \\
\hline
\end{tabular}

two reviewers, from each paper on to a standard record sheet. Disagreements were settled through discussion with a third reviewer.

Comparisons between studies, including potential determinants of outcome, were made and are presented in graphical form. Where determinants were measured quantitatively, we categorised them by tercile of study populations. For all metaanalyses, prevalence estimates were transformed to logits using the empirical logistic transformation and were later backtransformed. Significant heterogeneity was observed for both outcomes, and pooled estimates were derived using randomeffects methods. Meta-regressions were used to assess the effect of potential determinants on outcomes. Analyses were conducted using STATA V.9 using the "meta" and "metareg" commands.

\section{RESULTS}

What proportion of patients with occupational asthma recover symptomatically after cessation of exposure to the initiating antigen?

We identified 39 original papers that dealt with this question; they included 1681 patients and are summarised in table 1. The median follow-up period was 31 (range 6-240) months. In 33 studies, 1579 patients (94\%) were recruited from hospital clinics; far fewer patients $(n=102)$ were identified through workplace surveillance. A total of 25 papers were related to occupational asthma induced by low-molecular-weight (LMW) agents, in 11 cases di-isocyanates. Just four papers described outcomes from asthma induced only by high-molecular-weight (HMW) allergens (latex, crab proteins, flour and enzymes). The remainder ( 10 papers) were related to a variety of allergens.

The reported incidence of complete symptomatic recovery from asthma varied from $0 \%$ to $100 \%$, with a pooled prevalence of $32 \%$ (95\% confidence interval (CI) $26 \%$ to $38 \%$ ). They are displayed in fig 1, separately for studies in which diagnoses were made exclusively by specific inhalation testing. Figure 2 categorises the studies according to potential determinants of outcome. Pooled prevalences of complete symptomatic recovery were lower with increasing age $(p=0.019)$ and among clinicbased populations $(\mathrm{p}=0.053)$. Patients with the shortest durations of employment (up to 76 months) had the highest rate of recovery ( $36 \% ; 95 \%$ CI $25 \%$ to $50 \%$ ), but this pattern was not sustained at longer durations $(p=0.764)$. Eleven studies $^{5} 9111214192023244041$ reported durations of symptomatic exposure with a median of 26 months. Complete recovery was less common in those studies with an average duration of symptomatic exposure $>26$ months ( $35 \% \vee 48 \%$, respectively), although the difference was not significant $(p=0.12)$. In between-study comparisons, we found no clear patterns of recovery by duration of follow-up, by a crude index of study nationality or when comparing disease attributed to LMW or HMW agents. The median (range) age of patients in 22 studies of LMW agents was 39 (31-53) years and of those in 3 HMW studies was 32 (31-36) years. In all, 14 studies (475 patients), 2 of them workplace based ( 36 patients), seemed to report $100 \%$ follow-up. The pooled estimate of complete recovery in these 


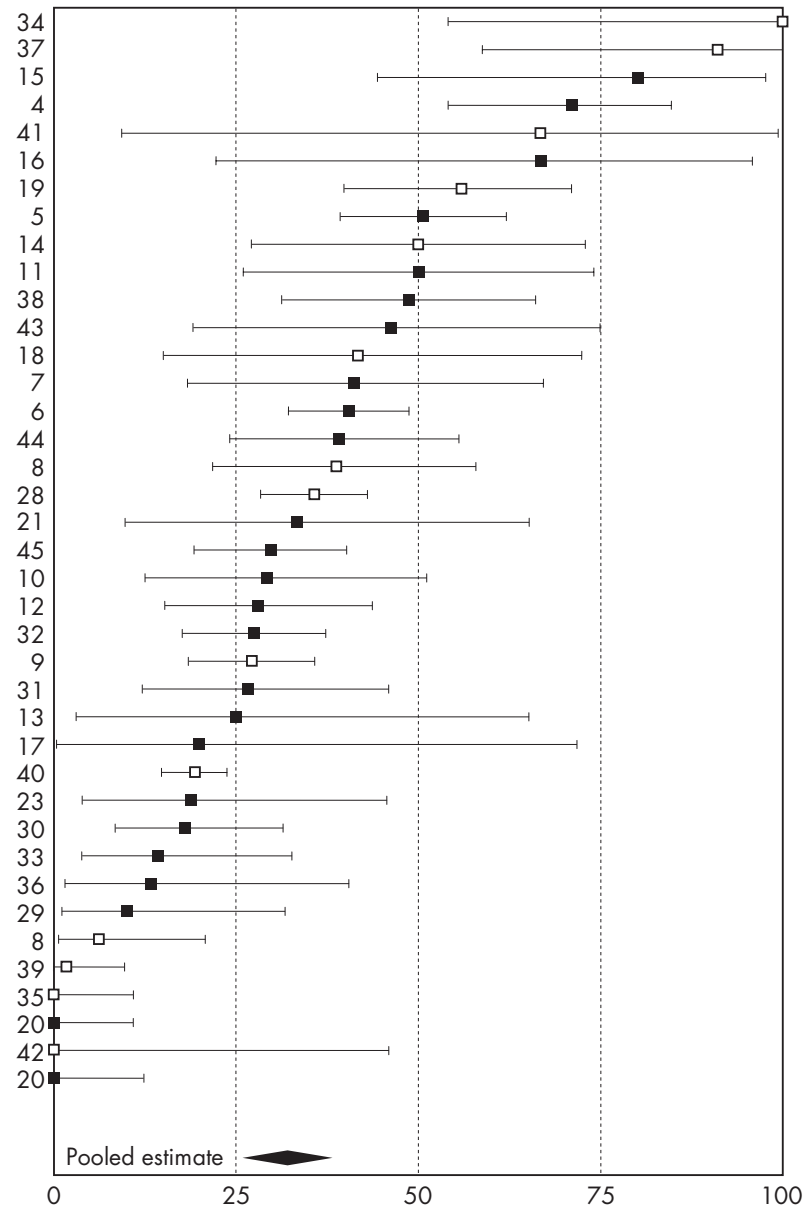

Figure 1 Proportion of subjects with complete symptomatic recovery from asthma at follow-up: individual and summary estimates. Black squares indicate studies where the diagnosis was made, in all subjects, by specific provocation testing. Study reference numbers are indicated on the left-hand axis.

was $40 \%$ (95\% CI $31 \%$ to $50 \%$ ). Among 23 studies (821 patients) with less complete follow-up, ranging from $21 \%$ to $91 \%$, the pooled prevalence of complete recovery was lower at only $27 \%$ ( $95 \%$ CI $20 \%$ to $37 \%$ ), although the difference was not significant $(\mathrm{p}=0.121)$.

Within-study comparisons of symptomatic recovery by age were available for 10 studies. $^{5} 7911121418384042$ In each, the mean age of patients with persistent symptoms was higher than that of patients who recovered; in two, the difference was statistically significant. ${ }^{72}$ Eleven studies included comparative information on total duration of exposure. . $^{79} 1112171820384042$ In all cases, patients with persisting symptoms of asthma had had longer exposures; in three studies ${ }^{711}{ }^{12}$ the differences were statistically significant. In 10 of the 11 reports examining the effect of the duration of symptomatic exposure, subjects who were asymptomatic at follow-up had shorter durations of symptoms than those who remained symptomatic. In five studies the association was statistically significant. ${ }^{79^{11}} 1^{12} 14$ We found no studies that examined the independent effects of age and exposure duration.

Eight reports examined the effects of smoking. ${ }^{7} 9111216233840$ Their findings were contradictory, with three studies ${ }^{911} 38$ reporting that patients who recovered completely were more likely to be smokers than those whose symptoms persisted, one study $^{40}$ the opposite and three studies reporting that there was

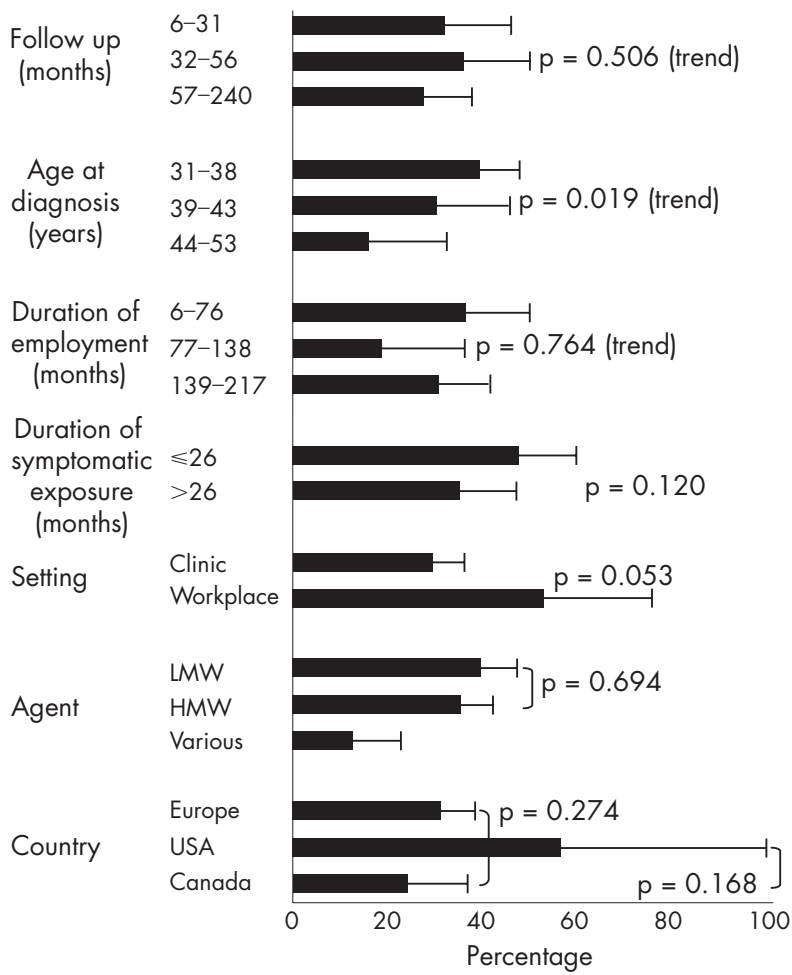

Figure 2 Determinants of complete symptomatic recovery from asthma. $\mathrm{HMW}$, high molecular weight; LMW, low molecular weight.

no relationship..$^{72}{ }^{16}$ The final paper ${ }^{23}$ stated that no statistical analysis was performed owing to the small sample size.

\section{What proportion of patients with occupational asthma recover physiologically after cessation of exposure to the offending agent?}

In all, 28 papers (695 subjects; 610 subjects from clinic-based populations and 85 from workplace-based studies) included sufficient information on physiological recovery with measures of NSBHR both at diagnosis and at follow-up (table 2). The median follow-up period was 37 (range 6-240) months. The pooled estimate of persistent NSBHR was $73 \%$, (95\% CI $66 \%$ to $79 \%$ ). Figure 3 shows the prevalence rates of hyper-responsiveness at diagnosis plotted against rates at follow-up.

In fig 4, these results are again categorised by potential determinants of outcome. Patients whose disease had been attributed to a LMW agent, and those from European workplaces, were less likely to have persistent NSBHR ( $p=0.006$ and 0.018 , respectively). The median (range) age of patients in 18 studies of LMW agents was 40 (31-53) years; for patients in 3 studies of HMW agents it was $36(32-37)$ years. Persistent hyper-reactivity was slightly less common among patients recruited through the workplace $(70 \% \vee 74 \%)$, but the difference was not significant $(p=0.561)$. We found no clear patterns of recovery by age or duration of either employment or follow-up.

We obtained data from two studies ${ }^{18}{ }^{25}$ regarding comparative information on age by recovery from NSBHR. In each, subjects who recovered physiologically were older than those who did not. Six studies ${ }^{8} 1517243647$ included information on duration of exposure; in five, a shorter duration of exposure was associated with better outcome in terms of physiological recovery. In one paper, ${ }^{24}$ no association was found. Two studies reported data on smoking, ${ }^{16}{ }^{24}$ neither showing a relationship with physiological recovery. 
Table 2 Characteristics of the reviewed studies of non-specific bronchial hyper-reactivity

\begin{tabular}{|c|c|c|c|c|c|c|c|c|}
\hline Year & Setting & Agent & $\begin{array}{l}\text { Subjects at } \\
\text { follow-up }\end{array}$ & $\begin{array}{l}\text { Follow-up } \\
\text { (months) }\end{array}$ & Agent(s) & Cut-off value (mg) & Country & Reference \\
\hline 1982 & Clinic & Colophony & 20 & 29 & Histamine & $\mathrm{PC}_{20} 16$ & Europe & Burge $^{6}$ \\
\hline 1982 & Clinic & Red cedar & 33 & 42 & Methacholine & $\mathrm{PC}_{20} 24$ & Canada & Chan-Yeung $^{7}$ \\
\hline 1984 & Clinic & Isocyanates & 12 & 25 & Bethanechol & $\mathrm{PC}_{15} \mathrm{NS}$ & Europe & Paggiaro $^{8}$ \\
\hline 1985 & Clinic & Crab & 31 & 12 & Histamine & $\mathrm{PC}_{20} \leqslant 16$ & Canada & Hudson? \\
\hline 1985 & Clinic & Various & 32 & 25 & Histamine & $\mathrm{PC}_{20} \leqslant 16$ & Canada & Hudson ${ }^{9}$ \\
\hline 1987 & Clinic & Isocyanates & 12 & 30 & Acetylcholine & $\mathrm{PC}_{15} \leqslant 0.1$ & Europe & Rosenberg $^{12}$ \\
\hline 1987 & Clinic & Isocyanates & 21 & 48 & $\begin{array}{l}\text { Histamine, cold } \\
\text { air }\end{array}$ & $\mathrm{PC}_{10} \mathrm{NS}$ & Europe & Lozewicz $^{10}$ \\
\hline 1988 & Clinic & Isocyanates & 30 & 10 & Methacholine & $\mathrm{PD}_{20}$ & Europe & Mapp $^{13}$ \\
\hline 1988 & Clinic & Crab & 31 & 64 & $\begin{array}{l}\text { Histamine, } \\
\text { methacholine }\end{array}$ & $\mathrm{PC}_{20} \leqslant 16$ & Canada & Mapp $^{43}$ \\
\hline 1988 & Clinic & Red cedar & 16 & 47 & Methacholine & $\mathrm{PC}_{20} \leqslant 16$ & Canada & Chan-Yeung $^{14}$ \\
\hline 1989 & Clinic & Various & 21 & 28 & Histamine & $\mathrm{PC}_{20} \leqslant 16$ & Canada & Allard ${ }^{15}$ \\
\hline 1989 & Workplace & Aluminium & 43 & 60 & Methacholine & $\mathrm{PC}_{20} \leqslant 8$ & New Zealand & $\mathrm{O}^{\prime}$ Donnell ${ }^{16}$ \\
\hline 1989 & Clinic & Various & 23 & 70 & Histamine & $\mathrm{PC}_{20} \leqslant 16$ & Canada & Allard ${ }^{15}$ \\
\hline 1990 & Clinic & Isocyanates & 10 & 22 & Methacholine & $\mathrm{PD}_{15} \leqslant 1$ & Europe & Paggiaro $^{44}$ \\
\hline 1992 & Clinic & Isocyanates & 6 & 6 & Methacholine & $\mathrm{PD}_{20} \leqslant 1.4$ & Europe & Saetta $^{18}$ \\
\hline 1992 & Workplace & Aluminium & 12 & 23 & Methacholine & $\mathrm{PC}_{20} \leqslant 16$ & Europe & Soyseth ${ }^{17}$ \\
\hline 1993 & Clinic & Isocyanates & 9 & 48 & Methacholine & $\mathrm{PD}_{20} \leqslant 1$ & Europe & Paggiaro ${ }^{45}$ \\
\hline 1994 & Workplace & Platinum salts & 24 & 19 & Methacholine & $\mathrm{PC}_{50}$ (SGaw) $\leqslant 8$ & Europe & Merget $^{24}$ \\
\hline 1994 & Clinic & Cobalt & 8 & 36 & Methacholine & $\mathrm{PD}_{15} \leqslant 1$ & Europe & Pisati $^{23}$ \\
\hline 1995 & Clinic & Isocyanates & 10 & 13 & Methacholine & $\mathrm{PD}_{20} \leqslant 1.4$ & Europe & Saetta $^{25}$ \\
\hline 1996 & Clinic & Various & 15 & 40 & Methacholine & $\mathrm{PC}_{20} \leqslant 16$ & Canada & Grammer $^{46}$ \\
\hline 1997 & Clinic & Isocyanates & 35 & 24 & Methacholine & $\mathrm{PC}_{20}$ (extrapolation) & Korea & Park \\
\hline 1998 & Clinic & Various & 42 & 37 & Methacholine & $\mathrm{PC}_{20} \leqslant 16$ & Europe & Perfetti ${ }^{47}$ \\
\hline 1998 & Clinic & Various & 33 & 107 & Methacholine & $\mathrm{PC}_{20} \leqslant 16$ & Europe & Perfetti ${ }^{47}$ \\
\hline 1998 & Workplace & Isocyanates & 6 & 240 & Histamine & $\mathrm{PC}_{20} \leqslant 16$ & Europe & Barker $^{48}$ \\
\hline 2002 & Clinic & Latex & 16 & 56 & Histamine & $\mathrm{PC}_{20} \leqslant 16$ & Europe & Vandenplas ${ }^{36}$ \\
\hline 2002 & Clinic & Isocyanates & 41 & 67 & Methacholine & $\mathrm{PC}_{20}$ (extrapolation) & Korea & Park ${ }^{37}$ \\
\hline 2004 & Clinic & Various & 103 & 104 & Methacholine & $\mathrm{PC}_{20} \leqslant 16$ & Canada & Maghni ${ }^{40}$ \\
\hline
\end{tabular}

NS, not significant; PC, previously calcified; PD, previously demineralised.

\section{DISCUSSION}

At face value, the findings of this systematic review are bleak; one third of patients with occupational asthma will recover fully from their disease despite avoidance of exposure to the initiating agent. This proportion seems not to be related to the duration of avoidance. In most cases, non-specific bronchial responsiveness detected at diagnosis persists. Significant between-study heterogeneity was observed for both outcomes, necessitating the use of random-effects methods to derive pooled estimates; given the extent of heterogeneity, we remain uneasy about their interpretation. Using the limited data available, we explored potential reasons for the variation. There was evidence that symptomatic outcomes worsened with increasing age and with duration of symptomatic exposure, although the latter was not significant. Routine surveillance programmes in high-risk working populations are based on the

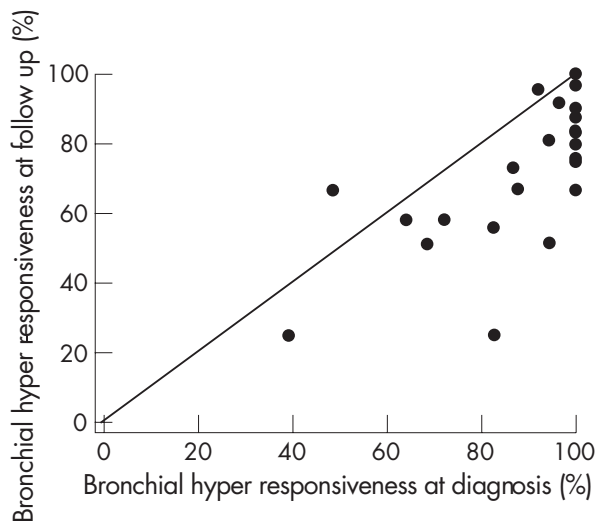

Figure 3 Proportion of patients with non-specific bronchial hyperreactivity at diagnosis and at follow-up. belief that patients with shorter durations of exposure have better symptomatic outcomes; interestingly, the relevant studies are largely of populations exposed to LMW compounds.

Most papers that we included were studies of patients recruited from and followed up through specialist clinics. The potential for bias here is high; patients with more severe disease may be referred more often for specialist assessment and those

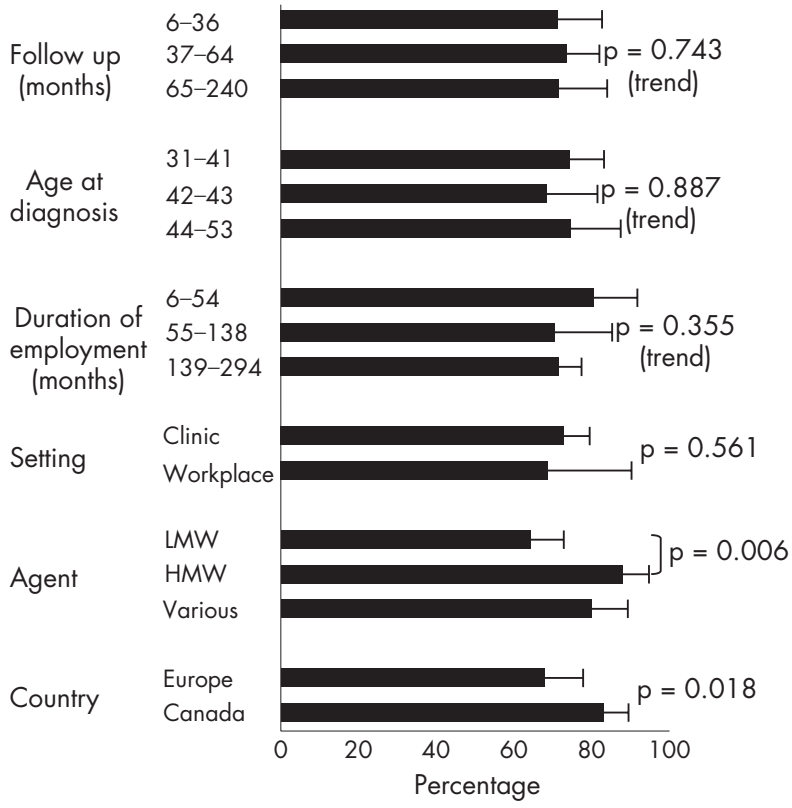

Figure 4 Determinants of persistent non-specific bronchial hyperreactivity at follow-up. HMW, high molecular weight; LMW, low molecular weight. 
with persistent disease more likely to be followed up. Issues surrounding the eligibility for continuing compensation may also be important. Together, these probably result in an underestimate of the true rate of recovery, and may explain why we were unable, when comparing different studies, to detect any consistent evidence of improvement with time. In 37 studies, where there was relevant information on the proportion of the base population included in the study, those with complete follow-up reported higher rates of symptomatic recovery, although this difference was not statistically significant. Six studies of symptoms and four of physiology were derived from workplace surveys, and thus probably included more representative populations. In these, the pooled prevalences of symptomatic recovery were higher in comparison with clinic based pooled estimates (53\% $v 30 \%$ ), although the difference was only borderline significant $(p=0.053)$. Workplace-based studies also showed a lower pooled prevalence of NSBHR at follow-up (70\% $v 74 \%)$, although the difference was smaller and not significant $(\mathrm{p}=0.561)$.

We acknowledge other limitations, most of them familiar to non-therapeutic systematic reviews. Studies were variable in their size and methods. In the absence of any agreed standard, we did not attempt to apply any quality criteria to those that we included, nor did we question the methods used to determine a diagnosis of occupational asthma, although these were certainly different. Confining our analysis to those studies where the diagnosis was established using specific provocation testing did not, however, reduce the variation in outcome. A further source of potential bias arises from the inclusion of several papers from the same research groups and the possibility that the study populations in them overlap. As they were widely available, and as we thought them to be clinically meaningful, we selected only two outcome variables from the many that have been reported. These, however, were not measured in a consistent manner, one (symptomatic recovery) being assessed using a variety of locally derived questionnaires or clinical information, the other (NSBHR) by a number of different agents and cut-off values. We elected not to include forced expiratory volume at $\mathrm{l} \mathrm{s}$ as an index of outcome as it is often normal at diagnosis. Nor did we include any measure of socioeconomic outcome; these are highly dependent on local circumstances, and comparisons between different studies from countries with different jurisdictions and employment patterns are unlikely to be fruitful. In addition, it was not possible to control for quantitative aspects of exposure (apart from duration), the severity of asthma at diagnosis or the use of protective equipment or anti-inflammatory treatment. Publication bias, whereby negative findings may be underreported and "established" associations reinforced, cannot of course be excluded.

It is widely accepted that the duration of (symptomatic) exposure to the causative allergen is an important determinant of outcome. In between-study comparisons of the 26 studies that reported the total duration of exposure (or employment), there was little evidence to support this; by contrast, 10 of the 11 studies that included information on symptomatic exposure reported that recovery from asthma was less frequent in those with longer durations, the difference being statistically significant in five studies $(p<0.05)$. Importantly, recovery was related to age in 10 studies (in two a significant association was reported); those studies in which the average age was lower reported higher rates of symptomatic recovery. Age and duration of exposure are likely to be related to each other, and it does not seem that their effects have been examined independently. Patients whose disease was attributed to HMW agents appeared in this review to fare more poorly in terms of physiology, an outcome that seems not to be confounded by age.
In several aspects, including the effects of allergen avoidance, occupational asthma provides a useful model for the study of adult asthma in the wider community. This may especially be so when the disease is caused by a workplace allergen of HMW although there are few outcome studies confined to these. The mechanisms of disease persistence after exposure avoidance are poorly understood; in the case of disease caused by crab aeroallergens, any recovery in lung function and NSBHR seems to take place in the first 2 years after exposure ceases. ${ }^{49}$ Persistence thereafter may be related to fixed airway remodelling, ${ }^{18} 2544$ which in turn may be related to age or the duration of allergen exposure. Retention of allergen or hapten in the lung, or extra-pulmonary tissue, has been suggested as a mechanism for continued IgE production after the cessation of external exposure to acid anhydrides ${ }^{50}$; in an animal model, IgE (and IgG) production has been shown even long after allergen exposure has stopped. ${ }^{51}$

An important function of a systematic review is the establishment of further research needs. Here, we have assembled and compared 39 studies of the symptomatic, and 28 of the functional, outcomes of occupational asthma. Considerable heterogeneity in their findings has been identified. It seems unarguable that a proportion of patients with occupational asthma do not recover from their disease. However, there is considerable uncertainty about the size and determinants of this proportion, a situation that creates difficulties for patients (and their advisers) needing to make important decisions about their employment. We suggest that clinicians and epidemiologists with an interest in this disease consider a large, necessarily collaborative and carefully standardised study of the prognosis of occupational asthma and its determinants after the avoidance of exposure.

\section{ACKNOWLEDGEMENTS}

We thank Magda Wheatley for her help in editing the manuscript.

\section{Authors' affiliations}

George Rachiotis, Rashna Savani, Andrew Brant, Stephanie J MacNeill, Anthony Newman Taylor, Paul Cullinan, Department of Occupational and Environmental Medicine, Imperial College (NHLI), London, UK

Competing interests: None.

\section{REFERENCES}

1 Chan-Yeung M. Occupational asthma. Clin Rev Allergy 1986;4:251-66.

2 McDonald JC, Chen Y, Zekveld C, et al. Incidence by occupation and industry of acute work related respiratory diseases in the UK, 1992-2001. Occup Environ Med 2005;62:836-42.

3 Nicholson PJ, Cullinan P, Taylor AJ, et al. Evidence based guidelines for the prevention, identification, and management of occupational asthma. Occup Environ Med 2005;62:290-9.

4 Meyer WC. Prognosis of occupational bronchial asthma after change of occupation and elimination of antigen. Münch Med Wochenschr 1977; 119:363-6

5 Chan-Yeung M. Fate of occupational asthma. A follow-up study of patients with occupational asthma due to western red Cedar (Thuja plicata). Am Rev Respir Dis 1977;116:1023-9.

6 Burge PS. Occupational asthma in electronics workers caused by colophony fumes: follow-up of affected workers. Thorax 1982;37:348-53.

7 Chan-Yeung M, Lam S, Koener S. Clinical features and natural history of occupational asthma due to western red cedar (Thuja plicata). Am J Med 1982;72:411-15

8 Paggiaro PL, Loi AM, Rossi O, et al. Follow-up study of patients with respiratory disease due to toluene diisocyanate. Clin Allergy 1984;14:463-9.

9 Hudson P, Cartier A, Pineau L, et al. Follow-up of occupational asthma caused by crab and various agents. J Allergy Clin Immunol 1985;76:682-8.

10 Lozewicz S, Assoufi BK, Hawkins R, et al. Outcome of asthma induced by isocyanates. $\mathrm{Br} J$ Dis Chest 1987:81:14-22.

11 Chan-Yeung M, Maclean L, Paggiaro PL. Follow-up study of 232 patients with occupational asthma caused by western red cedar (Thuja plicata). J Allergy Clin Immunol 1987;79:792-6.

12 Rosenberg N, Garnier R, Rousselin X, et al. Clinical and socio-professional fate of isocyanate-induced asthma. Clin Allergy 1987;17:55-61. 
13 Mapp CE, Corona PC, De Marzo N, et al. Persistent asthma due to isocyanates. A follow-up study of subjects with occupational asthma due to tolvene diisocyanate (TDI). Am Rev Respir Dis 1988;137:1326-9.

14 Chan-Yeung M, Leriche J, Maclean L, et al. Comparison of cellular and protein changes in bronchial lavage fluid of symptomatic and asymptomatic patients with red cedar asthma on follow-up examination. Clin Allergy 1988;18:359-65.

15 Allard C, Cartier A, Ghezzo H, et al. Occupational asthma due to various agents. Absence of clinical and functional improvement at an interval of four or more years after cessation of exposure. Chest 1989;96:1046-9.

16 O'Donnell TV, Welford B, Coleman ED. Potroom asthma: New Zealand experience and follow-up, Am J Ind Med 1989;15:43-9.

17 Soyseth V, Kongerud J, Boe J, et al. Bronchial responsiveness and work-related asthma in aluminium potroom workers: effect of removal from exposure. Eur Respir J 1992;5:829-33

18 Saetta M, Maestrelli P, Di Stefano A, et al. Effect of cessation of exposure to tolvene diisocyanate on bronchial mucosa of subjects with TDI-induced asthma. Am Rev Respir Dis 1992;145:169-74.

19 Pisati G, Baruffini A, Zedda S. Toluene diisocyanate induced asthma: outcome according to persistence or cessation of exposure. Br J Ind Med 1993;50:60-4.

20 Moscato G, Bertoletti R, Biscaldi G, et al. Occupational asthma: fate and management after the diagnosis. G ltal Med Lav 1993;15:27-31.

21 Marabini A, Dimich-Ward H, Kwan SY, et al. Clinical and socioeconomic features of subjects with red cedar asthma. A follow-up study. Chest 1993; 104:821-4.

22 Marabini A, Brugnami G, Curradi F, et al. The response to a specific bronchial provocation test and the evolution of occupational asthma. A longitudinal study in subjects with toluene diisocyanate-induced asthma. Med Lav 1994;85:134-41.

23 Pisati G, Zedda S. Outcome of occupational asthma due to cobalt hypersensitivity. Sci Total Environ 1994;150:167-71

24 Merget R, Reineke M, Rueckmann A, et al. Nonspecific and specific bronchial responsiveness in occupational asthma caused by platinum salts after allergen avoidance. Am J Respir Crit Care Med 1994;150:1146-9.

25 Saetta M, Maestrelli P, Turato G, et al. Airway wall remodeling after cessation of exposure to isocyanates in sensitized asthmatic subjects. Am J Respir Crit Care Med 1995; 151(2 Pt 1):489-94

26 Grammer LC, Shaughnessy MA, Hogan MB, et al. Study of employees with anhydride-induced respiratory disease after removal from exposure. J Occup Environ Med 1995;37:820-5.

27 Malo JL, Cartier A, Cote J, et al. Influence of inhaled steroids on recovery from occupational asthma after cessation of exposure: an 18-month double-blind crossover study. Am J Respir Crit Care Med 1996;153:953-60.

28 Lemiere C, Cartier A, Dolovich J, et al. Outcome of specific bronchia responsiveness to occupational agents after removal from exposure. Am J Respir Crit Care Med 1996; 154(Pt 1):329-33.

29 Grammer LC, Shaughnessy MA. Study of employees with anhydride-induced respiratory disease after removal from exposure. J Occup Environ Med 1996;38:771-4.

30 Park HS, Nahm DH. Prognostic factors for toluene diisocyanate-induced occupational asthma after removal from exposure. Clin Exp Allergy 1997;27: 1145-50.

31 Gassert TH, Hu H, Kelsey KT, et al. Long-term health and employment outcomes of occupational asthma and their determinants. J Occup Environ Med 1998;40:481-91

32 Ross DJ, McDonald JC. Health and employment after a diagnosis of occupational asthma: a descriptive study. Occup Med (Lond) 1998:48:219-25.
33 Sen D Wiley K Williams JG Occupational asthma in fruit salad processing. Clin Exp Allergy 1998;28:363-7.

34 Barker RD, Harris JM, Welch JA, et al. Occupational asthma caused by tetrachlorophthalic anhydride: a 12-year follow-up. J Allergy Clin Immuno 1998;101(Pt 1):717-19.

35 Moscato G, Dellabianca A, Perfetti L, et al. Occupational asthma: a longitudinal study on the clinical and socioeconomic outcome after diagnosis. Chest 1999;115:249-56.

36 Vandenplas O, Jamart J, Delwiche JP, et al. Occupational asthma caused by natural rubber latex: outcome according to cessation or reduction of exposure. J Allergy Clin Immunol 2002;109:125-30.

37 Park HS, Lee SK, Kim HY, et al. Specific immunoglobulin E and immunoglobulin $G$ antibodies to toluene diisocyanate-human serum albumin conjugate: useful markers for predicting long-term prognosis in tolvene diisocyanate-induced asthma. Clin Exp Allergy 2002;32:551-5.

38 Munoz X, Cruz MJ, Orriols R, et al. Occupational asthma due to persulfate salts: diagnosis and follow-up. Chest 2003;123:2124-9.

39 Padoan $M$, Pozzato V, Simoni $M$, et al. Long-term follow-up of toluene diisocyanate-induced asthma. Eur Respir J 2003;21:637-40.

40 Maghni K, Lemiere C, Ghezzo H, et al. Airway inflammation after cessation of exposure to agents causing occupational asthma. Am J Respir Crit Care Med 2004; 169:367-72.

41 Chan-Yeung M, Lam S, Koener S. Clinical features and natural history of occupational asthma due to western red cedar (Thuja plicata). Am J Med 1982;72:411-15

42 Saetta M, Maestrelli P, Turato G, et al. Airway wall remodeling after cessation of exposure to isocyanates in sensitized asthmatic subjects. Am J Respir Crit Care Med 1995;151(P+ 1):489-94.

43 Malo JL, Cartier A, Ghezzo H, et al. Patterns of improvement in spirometry, bronchial hyperresponsiveness, and specific lgE antibody levels after cessation of exposure in occupational asthma caused by snow-crab processing. Am Rev Respir Dis 1988;138:807-12.

44 Paggiaro $P$, Bacci E, Paoletti $P$, et al. Bronchoalveolar lavage and morphology of the airways after cessation of exposure in asthmatic subjects sensitized to tolvene diisocyanate. Chest 1990;98:536-42.

45 Paggiaro PL, Vagaggini B, Dente FL, et al. Bronchial hyperresponsiveness and tolvene diisocyanate. Long-term change in sensitized asthmatic subjects. Chest 1993;103:1123-8.

46 Lemiere C, Cartier A, Dolovich J, et al. Outcome of specific bronchial responsiveness to occupational agents after removal from exposure. Am J Respir Crit Care Med 1996;154(Pt 1):329-33

47 Perfetti L, Cartier A, Ghezzo H, et al. Follow-up of occupational asthma after removal from or diminution of exposure to the responsible agent: relevance of the length of the interval from cessation of exposure. Chest 1998;1 14:398-403.

48 Barker RD, Harris JM, Welch JA, et al. Occupational asthma caused by tetrachlorophthalic anhydride: a 12-year follow-up. J Allergy Clin Immuno 1998;101(Pt 1):717-9.

49 Malo JL, Ghezzo H. Recovery of methacholine responsiveness after end of exposure in occupational asthma. Am J Respir Crit Care Med 2004; 169:1304-7

50 Venables KM, Topping MD, Nunn AJ, et al. Immunologic and functional consequences of chemical (tetrachlorophthalic anhydride)-induced asthma after four years of avoidance of exposure. J Allergy Clin Immunol 1987:80:212-18.

51 Holt PG, Sedgwick JD, O'Leary C, et al. Long-lived lgE- and lgG-secreting cells in rodents manifesting persistent antibody responses. Cell Immunol 1984:89:281-9. 